\title{
A novel process of dye wastewater treatment by linking advanced chemical oxidation with biological oxidation
}

\author{
Haiming Zou*, Wanzheng Ma, Yan Wang \\ Anhui Science and Technology University, China \\ Department of Resource and Environment \\ *Corresponding author's e-mail: hmzou@126.com
}

\begin{abstract}
Keywords: dye wastewater, Fenton's oxidation, biological oxidation, biological aerated filter, advanced oxidation processes.
\end{abstract}

\begin{abstract}
Dye wastewater is one of typically non-biodegradable industrial effluents. A new process linking Fenton's oxidation with biological oxidation proposed in this study was investigated to degrade the organic substances from real dye wastewater. During the combination process, the Fenton's oxidation process can reduce the organic load and enhance biodegradability of dye wastewater, which is followed by biological aerated filter (BAF) system to further remove organic substances in terms of discharge requirement. The results showed that $97.6 \%$ of chemical oxygen demand (COD) removal by the combination process was achieved at the optimum process parameters: $\mathrm{pH}$ of $3.5, \mathrm{H}_{2} \mathrm{O}_{2}$ of $2.0 \mathrm{~mL} / \mathrm{L}, \mathrm{Fe}(\mathrm{II})$ of $500 \mathrm{mg} / \mathrm{L}, 2.0 \mathrm{~h}$ treatment time in the Fenton's oxidation process and hydraulic retention time (HRT) of $5 \mathrm{~h}$ in the BAF system. Under these conditions, COD concentration of effluent was $72.6 \mathrm{mg} / \mathrm{L}$ whereas $3020 \mathrm{mg} / \mathrm{L}$ in the influent, thus meeting the requirement of treated dye wastewater discharge performed by Chinese government (less than $100 \mathrm{mg} / \mathrm{L}$ ). These results obtained here suggest that the new process combining Fenton's oxidation with biological oxidation may provide an economical and effective alternative for treatment of non-biodegradable industrial wastewater.
\end{abstract}

\section{Introduction}

Dye production generally discharges large volumes of heavily-polluted wastewater belonging to one of the most difficult problems to be solved in industry, which may have a long-term negative impact on ecosystems when directly discharged into water bodies. Due to the existence of complicated chemical compounds (such as aromatic amines and nitroanilines) in dye wastewaters, it is commonly considered to be of very low biodegradability (Malachova et al. 2013, Papic et al. 2006), so-called persistent contaminant, which may have major threat to water environmental quality in some ways, especially potential contributions to lack of dissolved oxygen (DO) and increase of color. In this content, common biological treatment technologies for treatment of dye wastewaters will don't meet the requirement of discharge because of organic substances resistance to biodegradation. Advanced oxidation processes (AOPs) have been reported to a preferable method for the treatment of non-biodegradable industrial wastewaters (Chu et al. 2012, Mandal et al. 2010, Oller et al. 2011, Rizzo 2011). In AOPs, persistent organic pollutants can be degraded by hydroxyl radicals having high reactivity and non-selectivity (Comninellis et al. 2008, Shannon et al. 2008).

Among various AOPs, Fenton's oxidation process is widely recognized as one of the most promising technologies for stable and efficient removal rates in a dye wastewater treatment system because of its easy operation and high oxidation potential (Kang and Hwang 2000, Maezono et al. 2011, Manu and Mahamood 2011, Sun et al. 2009). In this process, catalytic decomposition of hydrogen peroxide $\left(\mathrm{H}_{2} \mathrm{O}_{2}\right)$ into highly reactive hydroxyl radicals $(\cdot \mathrm{OH})$ by means of $\mathrm{Fe}(\mathrm{II})$ was conducted under acidic conditions (Sanchis et al. 2013). Hydroxyl radicals have a strong oxidation capacity and can degrade varieties of organic compounds. More importantly, the Fenton's oxidation reaction is not influenced by wastewater characteristic, such as biodegradability, toxicity and salinity. However, Fenton's oxidation for completely degradation of organic compounds in wastewater is commonly expensive (compared with biological treatment method) because many intermediates generated during this oxidation process tend to be more and more antioxidative which requires a longer oxidation time, and thus, consumption of $\mathrm{H}_{2} \mathrm{O}_{2}$ and $\mathrm{Fe}(\mathrm{II})$ will increase with oxidation reaction time (Neyens and Baeyens 2003).

Recently, studies aiming at the application of Fenton's oxidation process into pretreatment of non-biodegradation industrial wastewaters have been reported (Chen et al. 2009, Chen et al. 2007, Padoley et al. 2011). In a Fenton's oxidation pretreatment process, the initially non-biodegradable organic compounds can be converted into more biodegradable intermediates, thus greatly enhancing the biodegradability of raw wastewaters (Vilar et al. 2012, Zhang et al. 2013). And then, 
the effluent from the pretreatment system was further treated in a biological oxidation process with a potentially lower cost. The feasibility of combination process of Fenton's oxidation coupled with biological oxidation for the treatment of non-biodegradation industrial wastewater has been demonstrated in the literature (Lodha and Chaudhari 2007, Oller et al. 2011, Papic et al. 2006). In the Fenton's oxidation followed by biological oxidation process, non-biodegradable organic compounds can be partially oxidized to easy biodegradable organic intermediates and then be completely degraded in biological treatment system. Compared with other biological treatment processes, biological aerated filter (BAF) is widely regarded as a promising fixed-film bioreactor for treatment of various types of wastewaters (Qiu et al. 2010), especially in application of advanced treatment of effluent from chemical or physical processes. The outstanding advantages of BAF are to perform biological oxidation of organic substances as well as physical filtration of suspended solids, to operate easily and to occupy less space (Feng et al. 2012a, Feng et al. 2012b).

The aim of this study was to assess the effectiveness of treatment dye wastewaters by a Fenton's oxidation process integrated with a BAF system in terms of the COD removal efficiency. Moreover, the effect of $\mathrm{pH}, \mathrm{H}_{2} \mathrm{O}_{2}$ dose, $\mathrm{Fe}$ (II) dose and treatment time of Fenton's oxidation of dye wastewater were investigated to find the optimum process parameters. The results obtained from this study, combining Fenton's oxidation with biological oxidation, may serve as a new suggestion for the treatment of dye wastewaters or non-biodegradable industrial wastewaters.

\section{Material and methods}

\section{Experimental setup and operation}

A schematic diagram of the experimental setup proposed in this study, operated continuously, mainly consisting of Fenton's oxidation reactor and BAF system is shown in Figure 1. The Fenton's reactor with a working volume of $3.5 \mathrm{~L}$, made of plexiglass, was carried out at room temperature $\left(21 \pm 2^{\circ} \mathrm{C}\right)$ and the operation procedure was performed as follows: 1) $\mathrm{Fe}(\mathrm{II})$ salt was added to the Fenton's oxidation reactor, (in this study
- ferrous sulfate $\left(\mathrm{FeSO}_{4}\right)$ ); 2) $\mathrm{H}_{2} \mathrm{O}_{2}$ solution was added under rapidly stirring (220 rpm used here); 3 ) $0.1 \mathrm{M}$ hydrochloric acid $(\mathrm{HCl})$ solution was added to adjust the $\mathrm{pH}$ to value required for experimental design in this study (see Table 1); 4) then, catalytic decomposition of hydrogen peroxide $\left(\mathrm{H}_{2} \mathrm{O}_{2}\right)$ into highly reactive hydroxyl radicals $(\mathrm{OH})$ by means of $\mathrm{Fe}(\mathrm{II})$ was conducted for $0.5 \mathrm{~h} \sim 3.5 \mathrm{~h}$ set here under slow stirring (40 rpm used here); 5) after completing the Fenton's oxidation reaction, $0.1 \mathrm{M}$ sodium hydroxide $(\mathrm{NaOH})$ was added to adjust the $\mathrm{pH}$ to $7.5 \pm 0.2$, followed by the settling for $25 \mathrm{~min}$; 6) effluent from the reactor was pumped to the subsequent BAF system and water samples were also collected for mensuration of COD concentration.

The BAF system made of plexiglass, having a downflow biofilter column, was $1.4 \mathrm{~m}$ in height and $0.1 \mathrm{~m}$ in internal diameter, packed with zeolite media (about $3 \mathrm{~mm}$ in diameter, $1050 \mathrm{~kg} / \mathrm{m}^{3}$ of stacking density, $11.2 \mathrm{~m}^{2} / \mathrm{g}$ of specific surface area and $43.5 \%$ of porosity) to a depth of $1 \mathrm{~m}$. Air was supplied by air pump at a flow rate of $1.3 \mathrm{~L} / \mathrm{min}$ to maintain the dissolved oxygen (DO) higher than $3 \mathrm{mg} / \mathrm{L}$. To remove excess biomass and solid particles absorbed on the surface of zeolite media, the BAF system was backwashed by the combination backwashing of gas and water in a counter-current manner for $72 \mathrm{~h}$ each using effluent from clarifying tank. The backwash procedure was composed of three steps: firstly, air was provided to the biofilter column at a flow rate of $6 \mathrm{~L} / \mathrm{min}$ for $3 \mathrm{~min}$; secondly, air and water were simultaneously added at the same flow rate of $5 \mathrm{~L} / \mathrm{min}$ for $5 \mathrm{~min}$; lastly, only water was pumped to the BAF system at a flow rate of $4 \mathrm{~L} / \mathrm{min}$ for $8 \mathrm{~min}$.

Effluent from the BAF system was introduced into the clarifying tank with length, width and height of $0.5 \mathrm{~m}$, $0.3 \mathrm{~m}$ and $0.4 \mathrm{~m}$, respectively, and after settling for $30 \mathrm{~min}$, partial supernatant in clarifying tank was used to backwash the biofilter column as described above and the rest was reused to produce dye.

\section{Biomass cultivation process in the BAF system}

In this study, the biomass cultivation process was completed within 35 days. During the biomass acclimatization period, the BAF reactor was firstly inoculated with seed sludge from

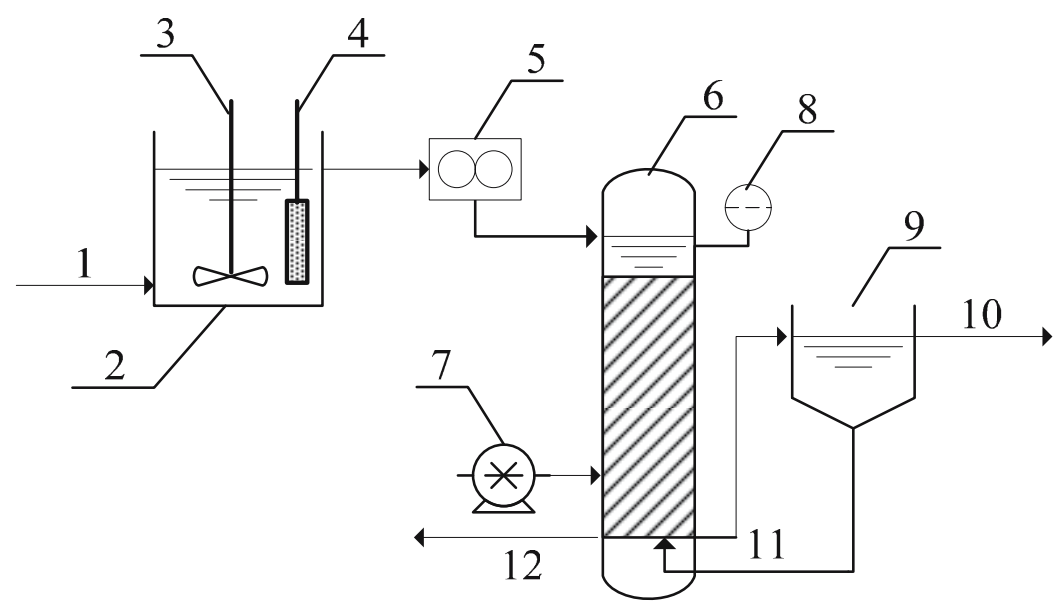

Fig. 1. Schematic diagram of experimental setup for dye wastewater treatment; 1 - influent, 2 - Fenton's oxidation reactor, 3 - stirrer, 4 - pH meter, 5 - flowmeter, 6 - BAF system, 7 - air pump (for aeration or backwash), 8 - content gage, 9 - clarifying tank, 10 - effluent, 11 - influent of backwash, 12 - effluent of backwash 
Table 1. Experimental procedures designed in this study

\begin{tabular}{|c|c|c|}
\hline Experimental stages & Process parameters & \\
\hline \multirow{4}{*}{ Fenton's oxidation } & $\mathrm{pH}$ & $\begin{array}{c}2,2.5,3,3.1,3.2,3.3,3.4,3.5,3.6,3.7,3.8 \\
3.9,4,4.5,5,5.5,6,6.5,7\end{array}$ \\
\hline & $\mathrm{H}_{2} \mathrm{O}_{2}$ dose $/\left(\mathrm{mL} \cdot \mathrm{L}^{-1}\right)$ & $0.5,1,1.5,2,2.5,3,3.5,4$ \\
\hline & $\mathrm{FeSO}_{4}$ dose $/\left(\mathrm{mg} \cdot \mathrm{L}^{-1}\right)$ & $300,350,400,450,500,550,600,650,700$ \\
\hline & Reaction time / h & $0.5,1,1.5,2,2.5,3,3.5$ \\
\hline Biological oxidation & \multicolumn{2}{|c|}{ Hydraulic Residence Time, HRT = $5 \mathrm{~h}$} \\
\hline
\end{tabular}

an aeration tank in the anaerobic-aerobic biological treatment process in Chemical Dye Industrial Factory, Fengyang, China, and then operated according to the following procedures: 1) operated in continuous flow mode with a low volumetric organic loading of $2.0 \mathrm{~kg} \mathrm{COD} /\left(\mathrm{m}^{3} \mathrm{~d}\right)$ and high hydraulic retention time (HRT) of $10 \mathrm{~h}$ for 15 days, and in this stage, the BAF system was not backwashed to improve the biomass accumulation process; 2) in the following 20 days, operated with a high loading of $4.0 \mathrm{~kg} \mathrm{COD} /\left(\mathrm{m}^{3} \mathrm{~d}\right)$ and low HRT of $5 \mathrm{~h}$, and during this stage, the BAF system was backwashed according the arrangement mentioned above to remove the excess biomass.

\section{Dye wastewater characterization}

The dye wastewaters used in this study were collected from the effluent of process of dye production (including Azaleine and Methyl Red) in a Chemical Dye Industrial Factory, Fengyang, China, in which the COD concentration was about $3020 \mathrm{mg} / \mathrm{L}$. COD was monitored according to the standard methods for the examination of water and wastewater (APHA 2002).

\section{Results and discussion}

\section{Effect of the initial solution pH on Fenton's oxidation}

Initial tests were conducted with varying solution $\mathrm{pH}$ at a constant addition of $\mathrm{H}_{2} \mathrm{O}_{2}$ of $2.5 \mathrm{~mL} / \mathrm{L}, \mathrm{Fe}$ (II) of $500 \mathrm{mg} / \mathrm{L}$, and a $2.0 \mathrm{~h}$ fixed treatment time. The solution $\mathrm{pH}$ used in this study was adjusted from 2 to 7 . The effect of $\mathrm{pH}$ on removal of organic substances from dye wastewaters, in the Fenton's oxidation reaction, are shown in Figure 2. It is observed that in all cases, the COD removal efficiency firstly increased rapidly but then dropped significantly with an increase in $\mathrm{pH}$ ranging from 2 to 7 ; an optimal range of COD removal efficiency by Fenton's oxidation was evident when $\mathrm{pH}$ was adjusted to 3.3 3.7 (in accordance with reports by Kallel et al. (2009)), at which over $83 \%$ of COD was removed. At an extremely low $\mathrm{pH}$ (about 2), the COD removal efficiency was low, only $39.2 \%$, probably due to the fact that the reaction rates of $\left[\mathrm{Fe}\left(\mathrm{H}_{2} \mathrm{O}\right)_{5} \mathrm{OH}\right]^{2+}$ and $\mathrm{H}_{2} \mathrm{O}_{2}$ were relatively low and - $\mathrm{OH}$ was strongly removed by much $\mathrm{H}^{+}$based on the Fenton's reaction mechanism described below, resulting in a more rapid decrease in COD removal efficiency (Szpyrkowicz et al. 2001). Moreover, the reaction between $\mathrm{Fe}(\mathrm{II})$ and $\mathrm{H}_{2} \mathrm{O}_{2}$ was inhibited under the high concentration of $\mathrm{H}^{+}$in solution (Nidheesh et al. 2013), leading to a decrease in Fe(II) generated from the reaction. Similarly, at a relatively high $\mathrm{pH}$ (above 4), the COD removal efficiency also dropped gradually and it was only $16.2 \%$ at the $\mathrm{pH}$ of 7 , mainly because under high $\mathrm{pH}$, auto decomposition of $\mathrm{H}_{2} \mathrm{O}_{2}$ was enhanced, iron ions were inactivated and transformed into iron oxyhydroxides, leading to the decrease in the amount of $\bullet \mathrm{OH}$ (Wang et al. 2009). The results obtained here were consistent with reported findings on the effectiveness of Fenton's oxidation process for treatment of non-biodegradable industrial wastewaters (Chu et al. 2012, Lee and Shoda 2008, Sari et al. 2012).

The Fenton's reaction mechanism can be described by the following chemical reactions (Kallel et al. 2009, Szpyrkowicz et al. 2001):

$$
\begin{gathered}
\mathrm{Fe}^{2+}+\mathrm{H}_{2} \mathrm{O}_{2} \rightarrow \mathrm{Fe}^{3+}+\mathrm{OH}^{-}+\mathrm{OH} \\
\mathrm{OH}+\mathrm{RH} \rightarrow \mathrm{H}_{2} \mathrm{O}+\mathrm{R}^{\cdot} \\
\mathrm{R}^{\cdot}+\mathrm{Fe}^{3+} \rightarrow \mathrm{R}^{+}+\mathrm{Fe}^{2+} \\
\mathrm{R}^{+}+\mathrm{H}_{2} \mathrm{O} \rightarrow \mathrm{ROH}+\mathrm{H}^{+} \\
\cdot \mathrm{OH}+\mathrm{H}_{2} \mathrm{O}_{2} \rightarrow \mathrm{H}_{2} \mathrm{O}+\mathrm{HO}_{2}^{\cdot} \\
\mathrm{HO}_{2}^{\cdot}+\mathrm{Fe}^{3+} \rightarrow \mathrm{Fe}^{2+}+\mathrm{O}_{2}+\mathrm{H}^{+} \\
\mathrm{Fe}^{3+}+\mathrm{H}_{2} \mathrm{O} \rightarrow \mathrm{HO}_{2}^{\cdot}+\mathrm{Fe}^{2+}+\mathrm{H}^{+} \\
\cdot \mathrm{OH}+\cdot \mathrm{OH} \rightarrow \mathrm{H}_{2} \mathrm{O}_{2}
\end{gathered}
$$

The above results showed that the initial solution $\mathrm{pH}$ is a key factor affecting the Fenton's oxidation performance, mainly because of its functions in determining the activities of catalytic reaction, oxidant and organic substances, the species of dominant iron ions (ferrous or ferric iron) and the stability of $\mathrm{H}_{2} \mathrm{O}_{2}$ capable of organic substances removal from dye wastewater (Duesterberg et al. 2008). In a suitable acidic environment, $\mathrm{pH}$ of 3.3-3.7 obtained in this study, Fe(II) was constantly produced. When decreasing solution $\mathrm{pH}$, corrosion rate of iron ions would be increased, leading to a decrease in the amount of $\mathrm{Fe}(\mathrm{II})$; with an increase in $\mathrm{pH}$, the gradual decline in COD removal efficiency may be attributed to $\mathrm{H}_{2} \mathrm{O}_{2}$ auto decomposition, low concentration and oxidation activity of $\bullet \mathrm{OH}$ and a decrease in catalytic reaction rate due to the generation of ferric hydroxide (Mackuak et al. 2012).

\section{Effect of $\mathrm{H}_{2} \mathrm{O}_{2}$ dosage on Fenton's oxidation}

For the study of the effect of $\mathrm{H}_{2} \mathrm{O}_{2}$ on dye wastewaters degradation in Fenton's oxidation process proposed in this study, the addition amount of $\mathrm{H}_{2} \mathrm{O}_{2}$ ranged from 0.5 to 4.0 $\mathrm{mL} / \mathrm{L}$, kept a constant concentration of $\mathrm{Fe}(\mathrm{II}) 500 \mathrm{mg} / \mathrm{L}$, at $\mathrm{pH}$ of 3.5 for $2.0 \mathrm{~h}$ of treatment time. These experimental results 


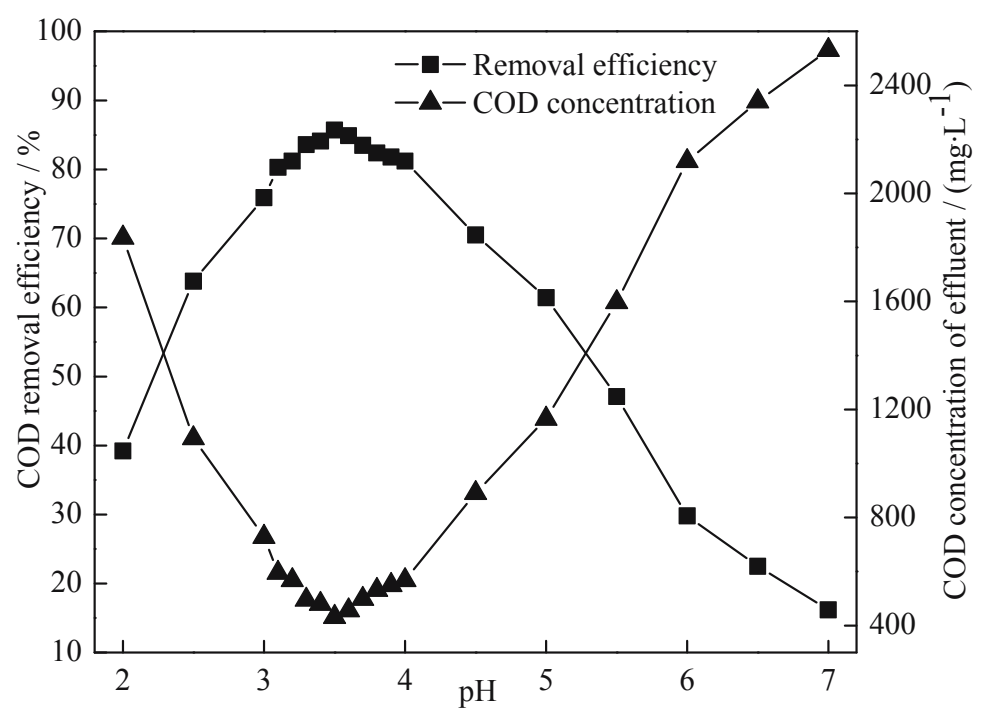

Fig. 2. Effect of the initial $\mathrm{pH}$ on COD removal efficiency from dye wastewater

are shown in Figure 3, presenting that the COD removal efficiency rapidly increased with an increase in $\mathrm{H}_{2} \mathrm{O}_{2}$ dosage, where the maximum COD removal efficiency of $86.2 \%$ was reached at the addition of $\mathrm{H}_{2} \mathrm{O}_{2} 2.5 \mathrm{~mL} / \mathrm{L}$. It can be explained on the basis of the fact that the produce of $\bullet \mathrm{OH}$ increases with an increase of $\mathrm{H}_{2} \mathrm{O}_{2}$ concentration in solution (Mandal et al. 2010), which effectively supported the reduction of organic substances in a Fenton's oxidation process.

However, no significant changes occurred or even slightly decreased in COD removal efficiency when the $\mathrm{H}_{2} \mathrm{O}_{2}$ dosage was more than $2.5 \mathrm{~mL} / \mathrm{L}$. Similar trends of inhibition of organic substances degradation by excessively high $\mathrm{H}_{2} \mathrm{O}_{2}$ concentration in solution were also observed in the report (Namkung et al. 2005) that COD removal efficiency decreased to about $58 \%$ when $\mathrm{H}_{2} \mathrm{O}_{2}$ dosage was added up to $0.056 \mathrm{~mol} / \mathrm{L}$. This reason may be because $\cdot \mathrm{OH}$ preferentially reacted with $\mathrm{H}_{2} \mathrm{O}_{2}$, and inhibited the oxidation reaction between organic substances and $\cdot \mathrm{OH}$ (Kallel et al. 2009), leading to the competition for $\cdot \mathrm{OH}$ between organic substances and $\mathrm{H}_{2} \mathrm{O}_{2}$. In addition, if the amount of $\mathrm{H}_{2} \mathrm{O}_{2}$ in solution is extremely low, the amount of $\bullet \mathrm{OH}$ generated in the reaction of $\mathrm{H}_{2} \mathrm{O}_{2}$ with $\mathrm{Fe}$ (II) would be inadequate to degrade organic substances. Although a maximum $86.2 \%$ COD removal efficiency can be obtained at the addition of $\mathrm{H}_{2} \mathrm{O}_{2} 2.5 \mathrm{~mL} / \mathrm{L}$, to save the dosage costs, $2.0 \mathrm{~mL} / \mathrm{L}$ of $\mathrm{H}_{2} \mathrm{O}_{2}$ added to the solution was regarded as a suitable amount, where the COD removal efficiency was $84.9 \%$ and the effluent of COD concentration was less than $500 \mathrm{mg} / \mathrm{L}$, meeting the requirement of subsequent biological oxidation treatment.

\section{Effect of Fe(II) dosage on Fenton's oxidation}

In the following experiments, the effect of $\mathrm{Fe}(\mathrm{II})$ concentration in solution on reduction of organic substances from dye wastewater was investigated in Fenton's oxidation process by varying the addition of $\mathrm{FeSO}_{4}$ from $300 \mathrm{mg} / \mathrm{L}$ to $700 \mathrm{mg} / \mathrm{L}$, while keeping the amount of $\mathrm{H}_{2} \mathrm{O}_{2}, \mathrm{pH}$ and treatment time constant at $2.0 \mathrm{~mL} / \mathrm{L}, 3.5$ and $2.0 \mathrm{~h}$ respectively. Figure 4 shows these experimental results. At a general glance, increased $\mathrm{Fe}(\mathrm{II})$ dosage effectively promoted the degradation of organic substances from dye wastewaters and higher COD removal efficiency was obtained with an increase in $\mathrm{Fe}(\mathrm{II})$ dosage. A maximum COD removal efficiency of $86.9 \%$ was reached when adding $\mathrm{Fe}$ (II) of $600 \mathrm{mg} / \mathrm{L}$, probably suggesting that higher $\mathrm{Fe}(\mathrm{II})$ amount may cause generation of more $\bullet \mathrm{OH}$ and gear up the Fenton's oxidation reaction between $\bullet \mathrm{OH}$ and organic substances. However, no significant changes in COD removal efficiency were observed when $\mathrm{Fe}$ (II) dosage increased further, higher than $600 \mathrm{mg} / \mathrm{L}$, which is consistent with the report by Wang et al. (2009), indicating that the formation of $\bullet \mathrm{OH}$ may be hindered when adding the excessive amount of $\mathrm{FeSO}_{4}$ to solution. Moreover, an extra $\mathrm{Fe}(\mathrm{II})$ concentration can lead to the generation of more $\mathrm{Fe}(\mathrm{III})$, which can react with $\mathrm{H}_{2} \mathrm{O}_{2}$ to produce $\mathrm{H}_{2} \mathrm{O}^{\circ}$ and the oxidation capacity of $\mathrm{H}_{2} \mathrm{O}^{\circ}$ is lower compared with $\bullet \mathrm{OH}$. Rozas et al. (2010) have also reported similar results that the COD removal efficiency decreased when lowering the ratio of $\mathrm{H}_{2} \mathrm{O}_{2} / \mathrm{Fe}$, which may be attributed to the excessive $\mathrm{H}_{2} \mathrm{O}_{2}$ competition with organic substances for -OH. Thus, the ratio of $\mathrm{H}_{2} \mathrm{O}_{2}$ to $\mathrm{Fe}(\mathrm{II})$ also determined strongly the Fenton's oxidation performance, apart from solution $\mathrm{pH}$. In this study, the optimum of $\mathrm{FeSO}_{4}$ concentration was $500 \mathrm{mg} / \mathrm{L}$ on the basis of economic costs and COD removal efficiency.

\section{Effect of treatment time on Fenton's oxidation}

In these tests that employed a constant addition of $\mathrm{H}_{2} \mathrm{O}_{2}$ $2.0 \mathrm{~mL} / \mathrm{L}$ and $\mathrm{Fe}(\mathrm{II}) 500 \mathrm{mg} / \mathrm{L}$ with $\mathrm{pH} 3.5$, the treatment time was set at $0.5,1.0,1.5,2.0,2.5,3.0$ and $3.5 \mathrm{~h}$ and it had a positive effect on organic substances reduction, as shown in Figure 5. In terms of COD removal efficiency, the degradation of organic substances gradually increased with the treatment time to reach $85.0 \%$ level at $1.5 \mathrm{~h}$ fixed time but no significant change was observed when the treatment time was above $1.5 \mathrm{~h}$. When treatment time increased from 1.5 to 3.5 , degradation levels of organic substances were greatly stable, and averaged $87.3 \%$ of COD removal efficiency. Similarly, Wang et al. (2012) found that an adequate treatment time during the Fenton's oxidation reaction favoured organic substances removal.

These abovementioned results suggest that the Fenton's oxidation has tremendous potential for oxidation of organic substances in dye wastewaters and the optimum process parameters were preferred as follows: $\mathrm{pH}=3.5, \mathrm{H}_{2} \mathrm{O}_{2}=$ 


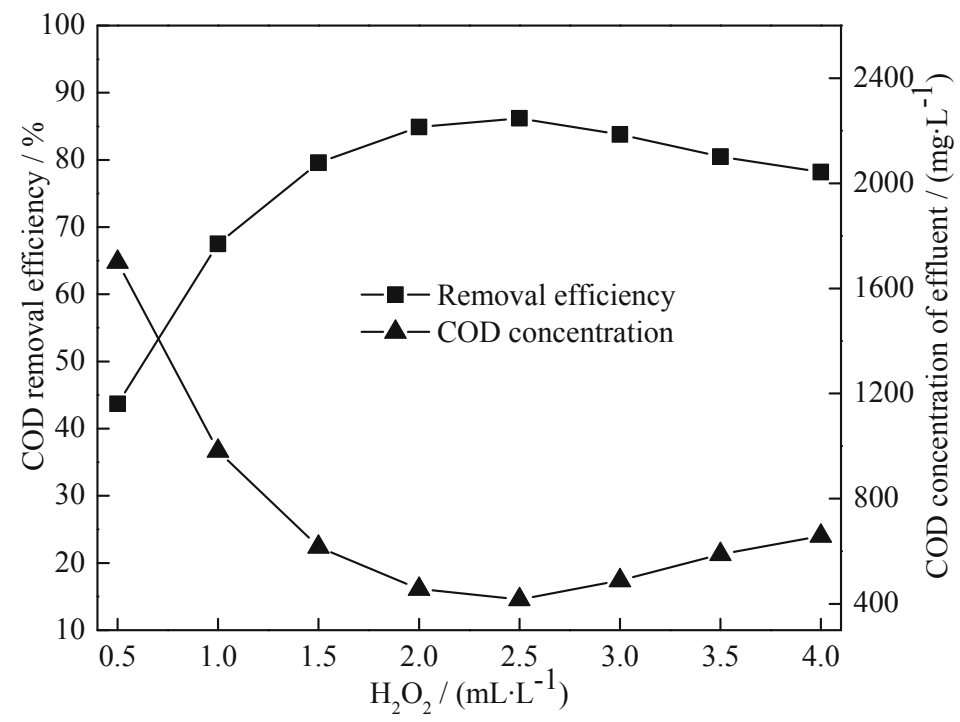

Fig. 3. Effect of $\mathrm{H}_{2} \mathrm{O}_{2}$ on COD removal efficiency from dye wastewater

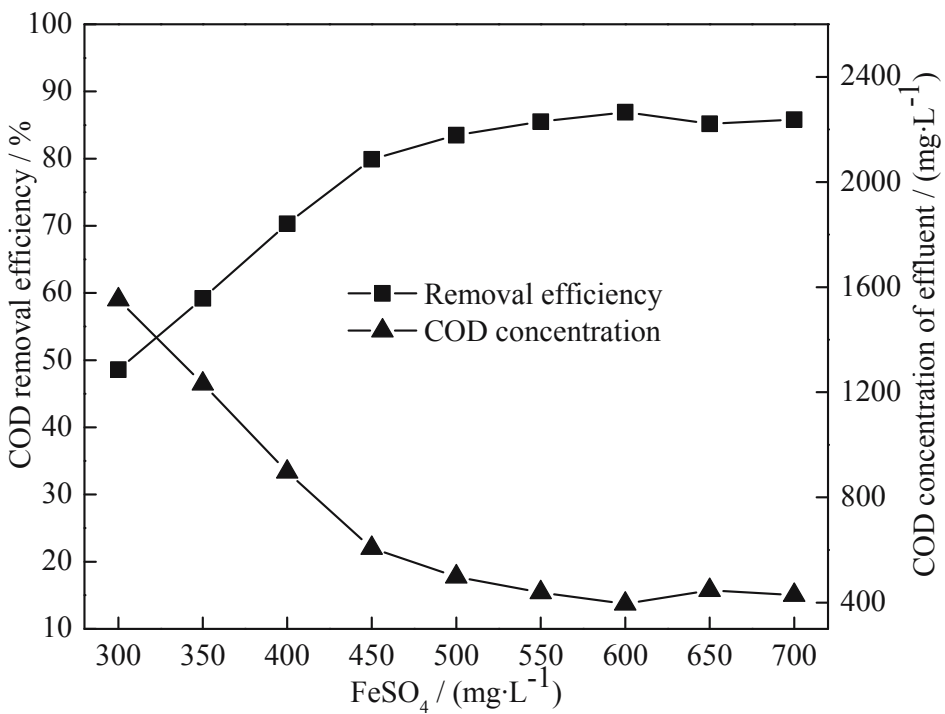

Fig. 4. Effect of $\mathrm{Fe}(\mathrm{II})$ on COD removal efficiency from dye wastewate

$2.0 \mathrm{~mL} / \mathrm{L}, \mathrm{Fe}(\mathrm{II})=500 \mathrm{mg} / \mathrm{L}$, and treatment time was $1.5 \mathrm{~h}$. Under these conditions the COD removal efficiency was $85.0 \%$, and the COD concentration in the effluent was less than $500 \mathrm{mg} / \mathrm{L}$ after Fenton oxidation when it was about $3020 \mathrm{mg} / \mathrm{L}$ in the influent.

\section{Linking Fenton's oxidation process with BAF system}

As described above, it has been proved that the Fenton's oxidation process played an important role in degradation of organic substances from dye wastewaters. To reduce the economic costs of treatment dye wastewaters by Fenton's oxidation, a BAF system was adopted to further degrade the organic substances from the effluent of Fenton's oxidation process by microbial oxidation in this study. Figure 6 shows the COD concentration of influent, the Fenton's oxidation process effluent and the BAF system effluent over 30 days. According to Figure 6, the averaged total COD removal efficiency over one month experimental period was $97.6 \%$ in the process linking Fenton's oxidation with biological oxidation, in which $85.9 \%$ of organic substances was removed in the Fenton's oxidation process and $11.7 \%$ in the BAF system. In addition, it was found that the organic substances removal performance was very stable and the averaged COD concentration of effluent in the combined process was $72.6 \mathrm{mg} / \mathrm{L}$, thus meeting the requirement of treated dye wastewater discharge performed by Chinese government (less than $100 \mathrm{mg} / \mathrm{L}$ ).

\section{Conclusions}

This study showed that the new method linking Fenton's oxidation with biological oxidation proposed here was effective strategy for organic substances removal from dye wastewater, exhibiting a good and stable COD removal performance.

The optimum process parameters, such as $\mathrm{pH}$, addition of $\mathrm{H}_{2} \mathrm{O}_{2}, \mathrm{Fe}(\mathrm{II})$ concentration and treatment time were 


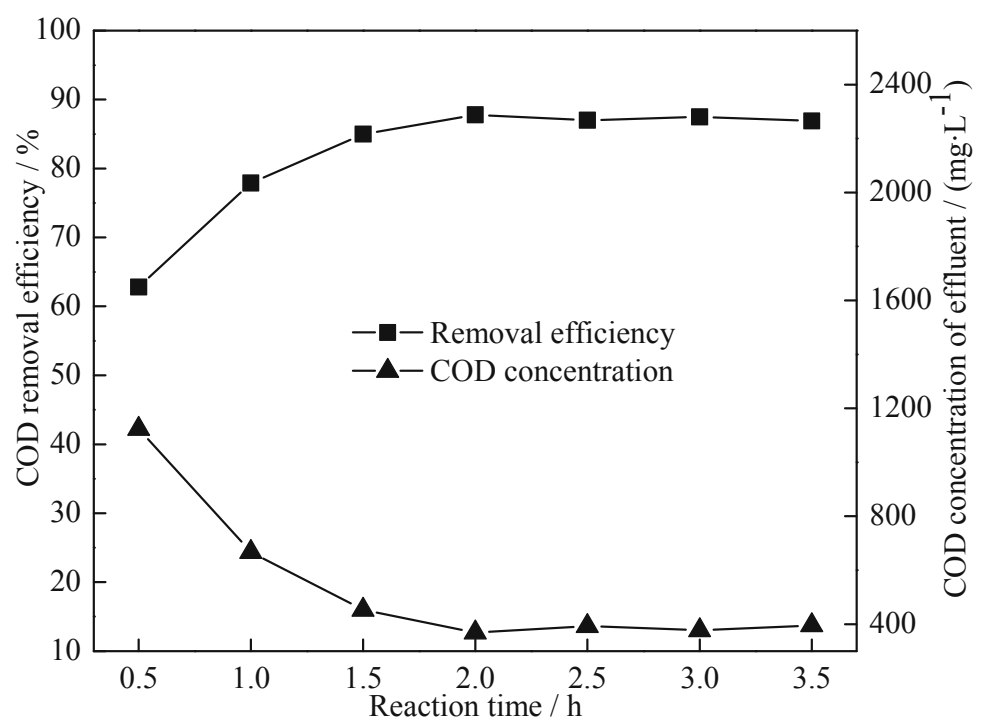

Fig. 5. Effect of treatment time on COD removal efficiency from dye wastewater

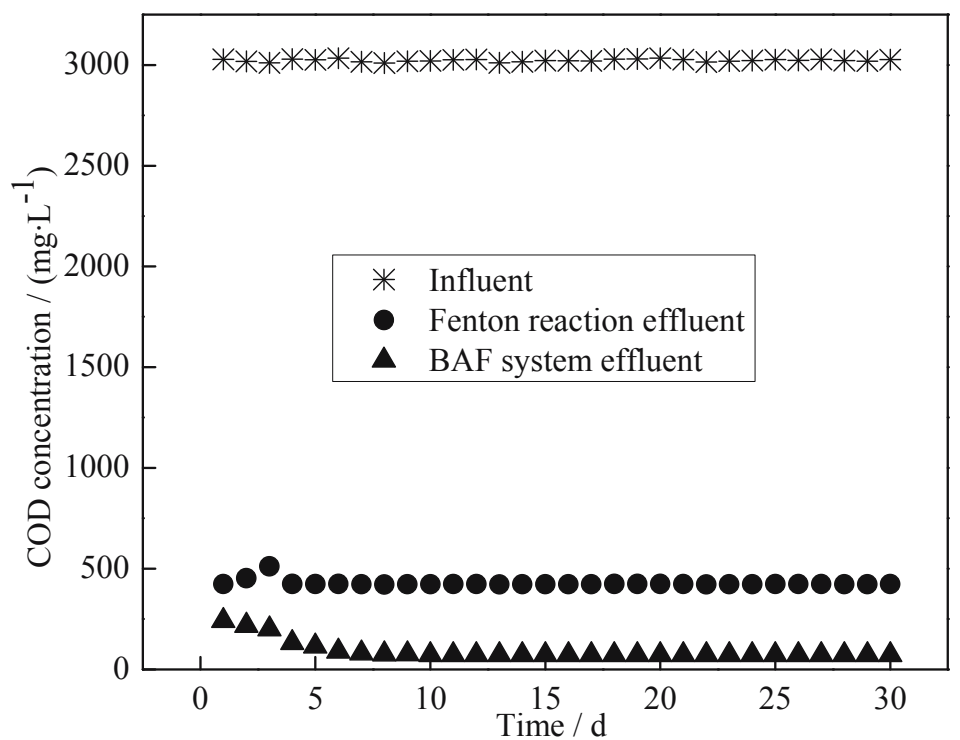

Fig. 6. Variations of COD concentration with time in the influent and effluent of Fenton's oxidation process and BAF system

3.5, $2.0 \mathrm{~mL} / \mathrm{L}, 500 \mathrm{mg} / \mathrm{L}$ and $2.0 \mathrm{~h}$, respectively. Under these conditions, total COD removal efficiency reached the maximum value, $97.6 \%$, and COD concentration in the effluent meet the discharge requirement performed by Chinese government.

From these results, the proposed system combining Fenton's oxidation with BAF technology can be an economical and effective method, probably being a promising technology for treatment of non-biological degradation industrial wastewater.

\section{Acknowledgements}

We wish to thank Dr. Wang for enlightening discussion. This research is supported by grant KJ2012B060 from Natural Science Foundation of the Ministry of Education of Anhui province and grant ZRC2013385 from Natural Science Foundation of Anhui Science and Technology University.

\section{References}

Chen, C., Wu, P. \& Chung, Y. (2009). Coupled biological and photo-Fenton pretreatment system for the removal of di-(2-ethylhexyl) phthalate (DEHP) from water, Bioresource Technology, 100, 19, pp. 4531-4534.

Chen, S., Sun, D. \& Chung, J. (2007). Treatment of pesticide wastewater by moving-bed biofilm reactor combined with Fenton-coagulation pretreatment, Journal of Hazardous Materials, 144, 1, pp. 577-584.

Chu, L., Wang, J., Dong, J., Liu, H. \& Sun, X. (2012). Treatment of coking wastewater by an advanced Fenton oxidation process using iron powder and hydrogen peroxide, Chemosphere, 86, 4, pp. 409-414.

Comninellis, C., Kapalka, A., Malato, S., Parsons, S.A., Poulios, I. \& Mantzavinos, D. (2008). Advanced oxidation processes for water treatment: advances and trends for R\&D, Journal of Chemical Technology and Biotechnology, 83, 6, pp. 769-776. 
Duesterberg, C.K., Mylon, S.E. \& Waite, T.D. (2008). pH effects on iron-catalyzed oxidation using Fenton's reagent, Environmental Science \& Technology, 42, 22, pp. 8522-8527.

Lee, H. \& Shoda, M. (2008). Removal of COD and color from livestock wastewater by the Fenton method, Journal of Hazardous Materials, 153, 3, pp. 1314-1319.

Feng, Y., Qi, J., Chi, L., Wang, D., Wang, Z., Li, K. \& Li, X. (2012a). Production of sorption functional media (SFM) from clinoptilolite tailings and its performance investigation in a biological aerated filter (BAF) reactor, Journal of Hazardous Materials, 246-247, 15, pp. 61-69.

Feng, Y., Yu, Y., Qiu, L., Zhang, J. \& Gao, L. (2012b). The characteristics and application of grain-slag media in a biological aerated filter (BAF), Journal of Industrial and Engineering Chemistry, 18, 3, pp. 1051-1057.

Kallel, M., Belaid, C., Boussahel, R., Ksibi, M., Montiel, A. \& Elleuch, B. (2009). Olive mill wastewater degradation by Fenton oxidation with zero-valent iron and hydrogen peroxide, Journal of Hazardous Materials, 163, 2, pp. 550-554.

Kang, Y.W. \& Hwang, K. (2000). Effects of reaction conditions on the oxidation efficiency in the Fenton process, Water Research, 34,10 , pp. 2786-2790.

Lodha, B. \& Chaudhari, S. (2007). Optimization of Fenton-biological treatment scheme for the treatment of aqueous dye solutions, Journal of Hazardous Materials, 148, 1, pp. 459-466.

Mackulák, T.ì., Smolinská, M., Olejniková, P., Prousek, J. \& Takáčová, A.B. (2012). Reduction of ostazine dyes' photodynamic effect by Fenton reaction, Chemical Papers, 66, 2, pp. 156-160.

Maezono, T., Tokumura, M., Sekine, M. \& Kawase, Y. (2011). Hydroxyl radical concentration profile in photo-Fenton oxidation process: Generation and consumption of hydroxyl radicals during the discoloration of azo-dye Orange II, Chemosphere, 82, 10, pp. 1422-1430.

Malachova, K., Rybkova, Z., Sezimova, H., Cerven, J. \& Novotny, C. (2013). Biodegradation and detoxification potential of rotating biological contactor (RBC) with Irpex lacteus for remediation of dye-containing wastewater, Water Research, 47, 19, pp. 7143-7148.

Mandal, T., Maity, S., Dasgupta, D. \& Datta, S. (2010). Advanced oxidation process and biotreatment: Their roles in combined industrial wastewater treatment, Desalination, 250, 1, pp. 87-94.

Manu, B. \& Mahamood, S. (2011). Enhanced degradation of paracetamol by UV-C supported photo-Fenton process over Fenton oxidation, Water Science \& Technology, 64, 12, pp. 2433-2438.

Namkung, K.C., Burgess, A.E. \& Bremner, D.H. (2005). A Fenton-like oxidation process using corrosion of iron metal sheet surfaces in the presence of hydrogen peroxide: a batch process study using model pollutants, Environmental Technology, 26, 3, pp. 341-352.

Neyens, E. \& Baeyens, J. (2003). A review of classic Fenton's peroxidation as an advanced oxidation technique, Journal of Hazardous Materials, 98, 1, pp. 33-50.

Nidheesh, P.V., Gandhimathi, R. \& Ramesh, S.T. (2013). Degradation of dyes from aqueous solution by Fenton processes: a review, Environmental Science and Pollution Research, 20, 4, pp. 2099-2132.

Oller, I., Malato, S. \& Sánchez-Pérez, J.A. (2011). Combination of advanced oxidation processes and biological treatments for wastewater decontamination-a review, Science of the Total Environment, 409, 20, pp. 4141-4166.
Padoley, K.V., Mudliar, S.N., Banerjee, S.K., Deshmukh, S.C. \& Pandey, R.A. (2011). Fenton oxidation: A pretreatment option for improved biological treatment of pyridine and 3-cyanopyridine plant wastewater, Chemical Engineering Journal, 166, 1, pp. 1-9.

Papic, S., Koprivanac, N., Bozic, A.L., Vujevic, D., Dragicevic, S.K., Kusic, H. \& Peternel, I. (2006). Advanced oxidation processes in azo dye wastewater treatment, Water Environment Research, 78, 6, pp. 572-579.

Qiu, L., Zhang, S., Wang, G. \& Du, M.A. (2010). Performances and nitrification properties of biological aerated filters with zeolite, ceramic particle and carbonate media, Bioresource Technology, 101, 19, pp. 7245-7251.

Rizzo, L. (2011). Bioassays as a tool for evaluating advanced oxidation processes in water and wastewater treatment, Water Research, 45, 15, pp. 4311-4340.

Rozas, O., Contreras, D., Mondaca, M.A., Pérez-Moya, M. \& Mansilla, H.D. (2010). Experimental design of Fenton and photo-Fenton reactions for the treatment of ampicillin solutions, Journal of Hazardous Materials, 177, 1, pp. $1025-1030$.

Sanchis, S., Polo, A.M., Tobajas, M., Rodriguez, J.J. \& Mohedano, A.F. (2014). Coupling Fenton and biological oxidation for the removal of nitrochlorinated herbicides from water, Water Research, 49, 1, pp. 197-206.

Sari, H., Yetilmezsoy, K., Ilhan, F., Yazici, S., Kurt, U. \& Apaydin, O. (2013). Fuzzy-logic modeling of Fenton's strong chemical oxidation process treating three types of landfill leachates, Environmental Science and Pollution Research, 20, 6, pp. $4235-4253$.

Shannon, M.A., Bohn, P.W., Elimelech, M., Georgiadis, J.G., Marinas, B.J. \& Mayes, A.M. (2008). Science and technology for water purification in the coming decades, Nature, 452, 7185, pp. 301-310.

Sun, S., Li, C., Sun, J., Shi, S., Fan, M. \& Zhou, Q. (2009). Decolorization of an azo dye Orange $G$ in aqueous solution by Fenton oxidation process: Effect of system parameters and kinetic study, Journal of Hazardous Materials, 161, 2, pp. 1052-1057.

Szpyrkowicz, L., Juzzolino, C. \& Kaul, S.N. (2001). A comparative study on oxidation of disperse dyes by electrochemical process, ozone, hypochlorite and Fenton reagent, Water Research, 35, 9, pp. 2129-2136.

Vilar, V.J.P., Moreira, F.C., Ferreira, A.C., Sousa, M.A., Gonçalves, C., Alpendurada, M.F. \& Boaventura, R.A. (2012). Biodegradability enhancement of a pesticide-containing bio-treated wastewater using a solar photo-Fenton treatment step followed by a biological oxidation process, Water Research, 46, 15, pp. 4599-4613.

Wang, C., Fu, H., Lu, Y. \& Zhao, X. (2012). Combined Fenton's oxidation and biological aerated filter process reduces chemical dosage, Environmental Engineering Science, 29, 4, pp. 248-254.

Wang, X., Chen, S., Gu, X. \& Wang, K. (2009). Pilot study on the advanced treatment of landfill leachate using a combined coagulation, fenton oxidation and biological aerated filter process, Waste Management, 29, 4, pp. 1354-1358.

Zhang, G., Qin, L., Meng, Q., Fan, Z. \& Wu, D. (2013). Aerobic SMBR/reverse osmosis system enhanced by Fenton oxidation for advanced treatment of old municipal landfill leachate, Bioresource Technology, 142, pp. 261-268. 